\title{
Effects of Long Chain Fatty Acids on Lipid and Glucose Metabolism in Monolayer Cultures of Bovine Hepatocytes
}

\author{
D. G. Mashek and R. R. Grummer ${ }^{1}$ \\ Department of Dairy Science \\ University of Wisconsin, Madison 53706
}

\begin{abstract}
The objectives were to determine the long-term (48 h) effects of specific long chain fatty acids on hepatic lipid and glucose metabolism in monolayer cultures of bovine hepatocytes. From 16 to $64 \mathrm{~h}$ after plating, hepatocytes from three 7- to 10-d-old calves were exposed to one of the following treatments: $1 \mathrm{~m} M$ palmitic acid (1 $\mathrm{m} M$ C16:0), $2 \mathrm{~m} M$ palmitic acid ( $2 \mathrm{~m} M$ C16:0), or 1 $\mathrm{m} M$ palmitic acid plus $1 \mathrm{~m} M$ of either stearic (C18:0), oleic (C18:1), linoleic (C18:2), linolenic (C18:3), eicosapentaenoic (C20:5), or docosahexaenoic (C22:6) acid, or $0.5 \mathrm{~m} M$ each of eicosapentaenoic and docosahexaenoic acid (C20:5 + C22:6). The two treatments containing 2 $\mathrm{m} M$ of saturated fatty acids, $2 \mathrm{~m} M$ C16:0 and $1 \mathrm{~m} M$ C16:0 plus $1 \mathrm{~m} M$ C18:0, increased $\beta$-hydroxybutyrate concentrations in the medium and $\left[1-{ }^{14} \mathrm{C}\right]$ palmitic acid oxidation to acid-soluble products compared with all other treatments. The treatment containing C22:6 increased total cellular triglyceride content and incorporation of $\left[1-{ }^{14} \mathrm{C}\right]$ palmitic acid into cellular triglycerides. The treatments containing C22:6 or C20:5 + C22:6 increased $\left[1-{ }^{14} \mathrm{C}\right]$ palmitic acid metabolism to phospholipids and cholesterol. The presence of C22:6 in the medium decreased metabolism of $\left[2-{ }^{14} \mathrm{C}\right]$ propionic acid either to glucose in the medium or to cellular glycogen. Overall, fatty acids differed in their effects on lipid and glucose metabolism in monolayer cultures of bovine hepatocytes with C22:6 eliciting the most profound changes.
\end{abstract}

(Key words: fatty acids, hepatic metabolism, monolayer cultures, fatty liver)

Abbreviation key: ASP = acid-soluble products, PUFA = polyunsaturated fatty acids, TG = triglyceride .

\footnotetext{
Received October 24, 2002.

Accepted February 8, 2003.

Corresponding author: R. R. Grummer; e-mail:grummer@calshp. cals.wisc.edu.

${ }^{1}$ Partially funded by: Bioproducts Inc., Church and Dwight, Diamond V, Degussa, Kemin Industries, Land O' Lakes/Farmland Feed, Archer Daniels Midland, Pioneer Hybrids and Zinpro.
}

\section{INTRODUCTION}

It is well documented in rodents and humans that the metabolic fate of a fatty acid depends upon its physical characteristics such as chain length, and number and configuration of double bonds. Recent research in our laboratory has confirmed these results in bovine hepatocytes. Mashek et al., (2002) showed that polyunsaturated fatty acids (PUFA) were poor substrates for incorporation into cellular triglyceride (TG) and several of the PUFA were preferentially oxidized compared with mono- or saturated fatty acids in 3-h cell suspensions of bovine hepatocytes. Additionally, different long chain fatty acids influenced the metabolism of palmitic acid, a common fatty acid in ruminant tissue.

Historically, fatty acids were thought to be inert molecules primarily used for energy storage and as membrane constituents. A growing body of research from a variety of species has shown that fatty acids are biologically active molecules that can regulate gene expression, enzyme activities, binding proteins, and other cellular processes (Sessler and Ntambi, 1998). Perhaps the most studied area of research involving fatty acids is their effect on lipid metabolism. Polyunsaturated fatty acids, especially $\mathrm{n}-3$, can increase mitochondrial and peroxisomal oxidation and decrease liver TG synthesis and storage (Ikeda et al., 1998; Ide et al., 2000).

Because of their ability to regulate lipid metabolism, PUFA have been used to modulate disorders in lipid metabolism in rodents and humans (Clarke, 2000). A common abnormality in lipid metabolism of dairy cattle is fatty liver. Periods of elevated adipose tissue catabolism, such as the time surrounding parturition, result in increased NEFA uptake into the liver and subsequent deposition as TG. The elevated TG content diminishes hepatic function and may be involved in the development of numerous metabolic disorders (Herdt, 1988; Veenhuizen et al., 1991; Bruss, 1993). For example, TG accumulation in cultured hepatocytes has been shown to decrease ureagenesis (Strang et al., 1998) and gluconeogenesis (Cadorniga-Valino et al., 1997). Therefore, identification of ways to alleviate fatty liver is important to improve animal health and productivity during the periparturient period. 
Many of the effects of PUFA on hepatic metabolism may not be realized when using short-term $(3 \mathrm{~h})$ cultures. Monolayer cultures of bovine hepatocytes provide a viable model for testing long-term effects of different fatty acids on hepatocyte function (Cadorniga-Valino, 1997; Strang et al., 1998). Therefore, our objectives were to determine the long-term ( $48 \mathrm{~h}$ ) effects of different long chain fatty acids on hepatic lipid and glucose metabolism in monolayer cultures of bovine hepatocytes.

\section{MATERIALS AND METHODS}

\section{Reagents}

Sodium thiopental was purchased from Abbott Laboratories (North Chicago, IL), Beuthanasia-D Special from Schering-Plough (Union, NJ), $\left[1-{ }^{14} \mathrm{C}\right]$ palmitic acid and $\left[2{ }^{14} \mathrm{C}\right]$ propionic acid from American Radiolabeled Chemicals, Inc. (St. Louis, MO), sodium salts of palmitic, stearic, oleic, linoleic, linolenic, eicosapentaenoic, docosahexaenoic, and propionic acid and Type IV collagenase from Sigma Chemical (St. Louis, MO), and BSA from Intergen (Purchase, NY). All other chemicals were cell culture grade and the highest available purity from Sigma Chemical (St. Louis, MO). Perfusion and wash media were as previously described (Donkin and Armentano, 1993). Incubation medium was Dulbecco's Modified Eagle's Medium containing $5.5 \mathrm{~m} M$ glucose, $10 \mathrm{~m} M$ HEPES, $4 \mathrm{~m} M$ L-glutamine, $1 \mathrm{~m} M$ pyruvate, and $25 \mathrm{mM} \mathrm{NaHCO}$.

\section{Hepatocytes and Treatments}

Three 7- to 10-d-old Holstein bull calves were anesthetized with $1.5 \mathrm{~g}$ sodium thiopental, the caudate process was removed, and hepatocytes were isolated as previously described (Donkin and Armentano, 1993). After removal of the caudate process, calves were killed with $10 \mathrm{ml}$ of Beuthanasia-D Special. Approximately $1.0 \times 10^{6}$ cells were seeded onto $35 \mathrm{~mm}$ Falcon Primaria culture dishes (Becton Dickinson, Lincoln Park, NJ) with $1.5 \mathrm{ml}$ of incubation medium containing $20 \%$ fetal bovine serum, $1 \mu M$ insulin, and $100 \mathrm{n} M$ dexamethasone. Cells were incubated at $37^{\circ} \mathrm{C}$ in $95 \%$ air: $5 \% \mathrm{CO}_{2}$. After $4 \mathrm{~h}$, the medium was replaced with one containing $10 \%$ fetal bovine serum, $100 \mathrm{n} M$ insulin, $100 \mathrm{IU} / \mathrm{ml}$ penicillin, $100 \mu \mathrm{g} / \mathrm{ml}$ streptomycin, $250 \mathrm{ng} / \mathrm{ml}$ amphotericin, and $2.5 \mathrm{mM}$ propionic acid. The medium was changed again at $16 \mathrm{~h}$ after seeding and was the same as the previous medium except insulin was reduced to $10 \mathrm{n} M$ and $1 \mathrm{~m} M$ carnitine was added. Additionally, the following treatments were applied at $16 \mathrm{~h}$ after seeding: $1 \mathrm{~m} M$ palmitic acid ( $1 \mathrm{~m} M$ C16:0), $2 \mathrm{~m} M$ palmitic acid (2 $\mathrm{m} M \mathrm{C} 16: 0)$, or $1 \mathrm{~m} M$ palmitic acid plus
$1 \mathrm{~m} M$ of either stearic (C18:0), oleic (C18:1), linoleic (C18:2), linolenic (C18:3), eicosapentaenoic (C20:5), or docosahexaenoic acid (C22:6), or $0.5 \mathrm{mM}$ of each $\mathrm{C} 20: 5$ and C22:6. All fatty acids were bound to albumin in a 4:1 molar ratio. One set of triplicate dishes for each treatment contained $\left[1-{ }^{14} \mathrm{C}\right]$ palmitic acid while another set of triplicate dishes contained no radioactivity. An additional treatment containing bovine BSA without fatty acids was included for the measurements not involving $\left[1-{ }^{14} \mathrm{C}\right]$ palmitic acid. The medium was changed at $45 \mathrm{~h}$ after initiation of treatments for an additional set of triplicate dishes per treatment. The new medium contained $2.5 \mathrm{mM}\left[2-{ }^{14} \mathrm{C}\right]$ propionic acid to measure the conversion of propionic acid to medium glucose and cellular glycogen in the presence of the fatty acid treatments. All incubations were terminated at 48 after initial treatments were applied.

\section{Measurements and Analysis}

For the dishes containing $\left[1-{ }^{14} \mathrm{C}\right]$ palmitic acid, the medium was removed and the cells were washed twice with Krebs Buffer and then frozen with $1 \mathrm{ml}$ of a dissociation buffer as previously described (Donkin and Armentano, 1993). An aliquot of the medium was used to determine $\left[1-{ }^{14} \mathrm{C}\right]$ palmitic acid metabolism to acidsoluble products (ASP) as previously described (Mashek et al., 2002). The cells were scraped from the dishes and both the cells and medium were extracted (Folch et al., 1957) and spotted on TLC plates for measurement of $\left[1-{ }^{14} \mathrm{C}\right]$ palmitic acid metabolism to cellular lipids and medium TG (Mashek et al., 2002).

The cells in dishes containing no radiolabeled fatty acids were treated the same as above. However, after separation of lipid classes by TLC, spots corresponding to TG and phospholipid were scraped, extracted with chloroform:methanol (2:1), and methylated (Sukhija and Palmquist, 1988) for determination of fatty acid composition by gas chromatography. Medium was analyzed for $\beta$-hydroxybutyrate as previously described (Mashek and Beede, 2001).

For the dishes containing $\left[2-{ }^{14} \mathrm{C}\right]$ propionic acid, the medium was removed and the dishes were washed twice with $1 \mathrm{ml}$ Krebs Buffer and added to the original medium. The medium was frozen for later analysis of $\left[{ }^{14} \mathrm{C}\right]$ glucose (Mills et al., 1981) and the cells were analyzed for $\left[{ }^{14} \mathrm{C}\right]$ glycogen content as previously described (Hue et al., 1975). The method of LaBarca and Paigen (1980) was used to determine DNA concentrations.

\section{Statistical Analysis}

Data were analyzed using the Mixed Procedure of SAS (SAS, 1999). The model included fixed effects of 
Table 1. Least-squares means for $\left[1-{ }^{14} \mathrm{C}\right]$ palmitic acid metabolism to acid-soluble products and triglyceride in the medium, and cellular lipids.

\begin{tabular}{|c|c|c|c|c|c|c|c|c|c|c|}
\hline & $\begin{array}{l}1 \mathrm{~m} M \\
\mathrm{C} 16: 0^{1}\end{array}$ & $\begin{array}{l}2 \mathrm{~m} M \\
\mathrm{C} 16: 0\end{array}$ & $\begin{array}{l}\text { C16:0 } \\
\text { C18:0 }\end{array}$ & $\begin{array}{l}\text { C16:0 } \\
\text { C18:1 }\end{array}$ & $\begin{array}{l}\text { C16:0 } \\
\text { C18:2 }\end{array}$ & $\begin{array}{l}\text { C16:0 } \\
\text { C18:3 }\end{array}$ & $\begin{array}{l}\text { C16:0 } \\
\text { C20:5 }\end{array}$ & $\begin{array}{l}\text { C16:0 } \\
\text { C22:6 }\end{array}$ & $\begin{array}{l}\text { C16:0 } \\
\text { C20:5+C22:6 }\end{array}$ & SEM \\
\hline & & & & - $(\mathrm{n}$ & oles/ $\mu \mathrm{g} \mathrm{D}$ & $\mathrm{A} \times 48 \mathrm{~h})$ & & & & \\
\hline Acid-soluble products & $8.76^{\mathrm{b}}$ & $27.32 *$ & $16.94^{\mathrm{a}}$ & $7.54^{\mathrm{b}}$ & $7.21^{\mathrm{b}}$ & $9.89^{\mathrm{b}}$ & $9.30^{\mathrm{b}}$ & $8.26^{\mathrm{b}}$ & $9.74^{\mathrm{b}}$ & 3.09 \\
\hline Triglyceride & $0.51^{\mathrm{bc}}$ & $1.51^{*}$ & $0.74^{\mathrm{a}}$ & $0.42^{\text {cd }}$ & $0.35^{\mathrm{d}}$ & $0.55^{\mathrm{abc}}$ & $0.49^{\mathrm{bc}}$ & $0.65^{\mathrm{ab}}$ & $0.58^{\mathrm{abc}}$ & 0.15 \\
\hline \multicolumn{11}{|l|}{ Cell } \\
\hline Triglyceride & $18.79^{\mathrm{d}}$ & $45.54^{*}$ & $26.21^{\mathrm{bc}}$ & $24.49^{\mathrm{bc}}$ & $22.75^{\text {cd }}$ & $26.85^{\mathrm{bc}}$ & $25.31^{\mathrm{bc}}$ & $35.71^{\mathrm{a}}$ & $28.97^{\mathrm{b}}$ & 3.17 \\
\hline Cholesterol esters & 0.42 & $0.76^{*}$ & 0.44 & 0.37 & 0.40 & 0.40 & 0.36 & 0.41 & 0.41 & 0.06 \\
\hline Fatty acids & $0.85^{\mathrm{cd}}$ & $2.10^{*}$ & $1.27^{\mathrm{a}}$ & $0.71^{\mathrm{d}}$ & $1.04^{\mathrm{bc}}$ & $0.92^{\mathrm{cd}}$ & $0.98^{c}$ & $1.34^{\mathrm{a}}$ & $1.21^{\mathrm{ab}}$ & 0.18 \\
\hline
\end{tabular}

treatment, random effects of calf, and residual error term. If treatment was significant in the model, differences between treatments were determined using the PDIFF procedure of SAS. Because the $2 \mathrm{~m} M$ C16:0 treatment contained $2 \mathrm{mM}$ labeled palmitic acid, it was not included in the multicomparison tests with the remaining treatments containing $1 \mathrm{~m} M$ labeled palmitic acid. Instead, a contrast comparing $1 \mathrm{~m} M$ C16:0 versus $2 \mathrm{mM}$ C16:0 was used to test the effects of $\mathrm{C} 16: 0$ concentration. For all comparisons, significance was declared at $P<0.05$.

\section{RESULTS AND DISCUSSION}

\section{Oxidation}

The primary end-products of fatty acid oxidation are ketone bodies and $\mathrm{CO}_{2}$, however, $\mathrm{CO}_{2}$ can not be measured in monolayer culture incubations. Therefore, the only measurement of oxidation in the present study was the metabolism of $\left[1-{ }^{14} \mathrm{C}\right]$ palmitic acid to ASP, which are indicators of ketone body production, and $\beta$-hydroxybutyrate concentrations in the medium. As shown in Table 1, increasing the palmitic acid concentration from 1 to $2 \mathrm{mM}$ tripled its incorporation into ASP. The treatment containing C18:0 resulted in the highest rates of $\left[1-{ }^{14} \mathrm{C}\right]$ palmitic acid metabolism to ASP compared to all other fatty acids tested. The $\beta$-hydroxybutyrate concentrations in the medium were highest for the treatment containing C18:0 and the $2 \mathrm{mM}$ C16:0 treatment, which were different from all other treatments (Figure 1). The remaining treatments, with the exception of that containing C18:1, had similar $\beta$ hydroxybutyrate concentrations to the BSA control containing no fatty acids. In general, PUFA increase hepatic fatty acid oxidation (Clarke, 2000). Therefore, the increased palmitic acid metabolism to ASP and in- creased concentrations of $\beta$-hydroxybutyrate in the medium for treatments containing saturated fatty acids conflicts with the general understanding of fatty acid metabolism in rodents and humans. In previous shortterm $(3 \mathrm{~h})$ cultures of bovine hepatocytes, C20:5 and C22:6 had higher rates of oxidation to $\mathrm{CO}_{2}$ and increased oxidation of palmitic acid to $\mathrm{CO}_{2}$ and ASP compared with C16:0 (Mashek et al., 2002). The reasons for the increased oxidation of saturated fatty acids to ASP in the current study are not known.

\section{Cellular and Medium Lipids}

Increasing the concentration of palmitic acid in the medium from 1 to $2 \mathrm{mM}$ increased $\left[1-{ }^{14} \mathrm{C}\right]$ palmitic acid incorporation into cellular TG by $142 \%$ (Table 1 ). The highest rate of $\left[1-{ }^{14} \mathrm{C}\right]$ palmitic acid incorporation into cellular TG was for the treatment containing C22:6, which was significantly different from all other treatments. The lowest rates of $\left[1-{ }^{14} \mathrm{C}\right]$ palmitic acid metabolism to cellular TG were obtained for the $1 \mathrm{~m} M$ C16 treatment.

Increasing the concentration of palmitic acid from 0 (i.e., BSA) to $1 \mathrm{mM}$ and from 1 to $2 \mathrm{mM}$ increased total cellular TG content as expected (Figure 2). Within treatments containing a total of $2 \mathrm{~m} M$ of fatty acids, total cellular TG was highest for the treatments containing C22:6, either 0.5 or $1 \mathrm{~m} M$, and lowest for 2 $\mathrm{m} M$ C16:0 followed by the treatment containing C18:3 (Figure 2). Previous 3-h incubations of ruminant hepatocytes showed that incorporation of $1 \mathrm{~m} M$ palmitic acid into cellular TG was similar with or without the addition of $1 \mathrm{~m} M$ C22:6 (Mashek et al., 2002). The same study also showed that PUFA were poor substrates for incorporation into cellular TG. Most feeding studies in rodents have shown a decrease in liver TG content in 


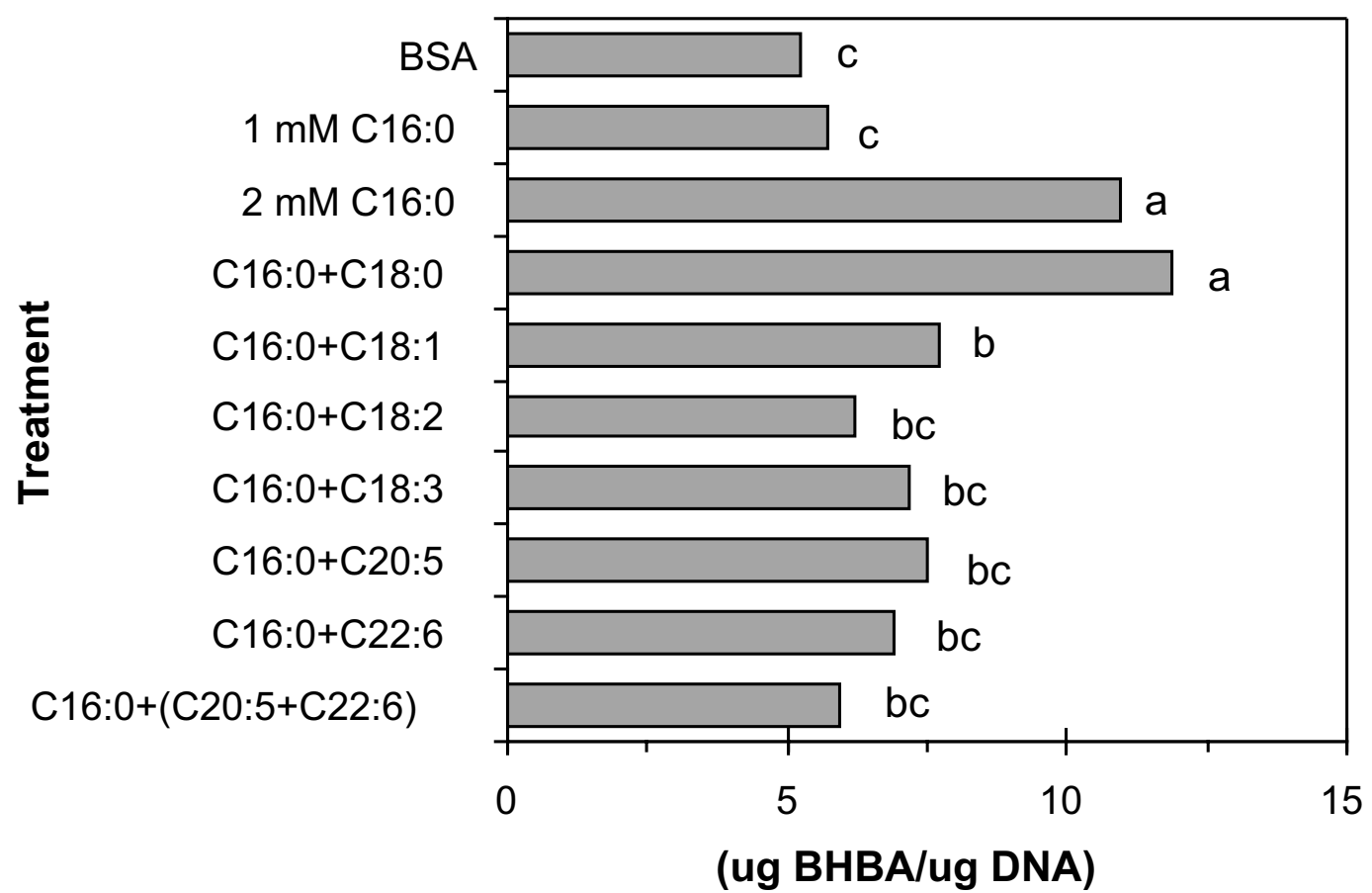

Figure 1. Total $\beta$-hydroxybutyric content in medium per $\mu \mathrm{g}$ of cellular DNA. Treatments were BSA, $1 \mathrm{~m} M \mathrm{C} 16: 0,2 \mathrm{~m} M \mathrm{C} 16: 0$, and 1 $\mathrm{m} M$ C16:0 plus $1 \mathrm{~m} M$ of either C18:0, C18:1, C18:2, C18:3, C20:5, C22:6, or 0.5 mM of C20:5 and C22:6. Treatments with unlike letters differ $(P<0.05)$.

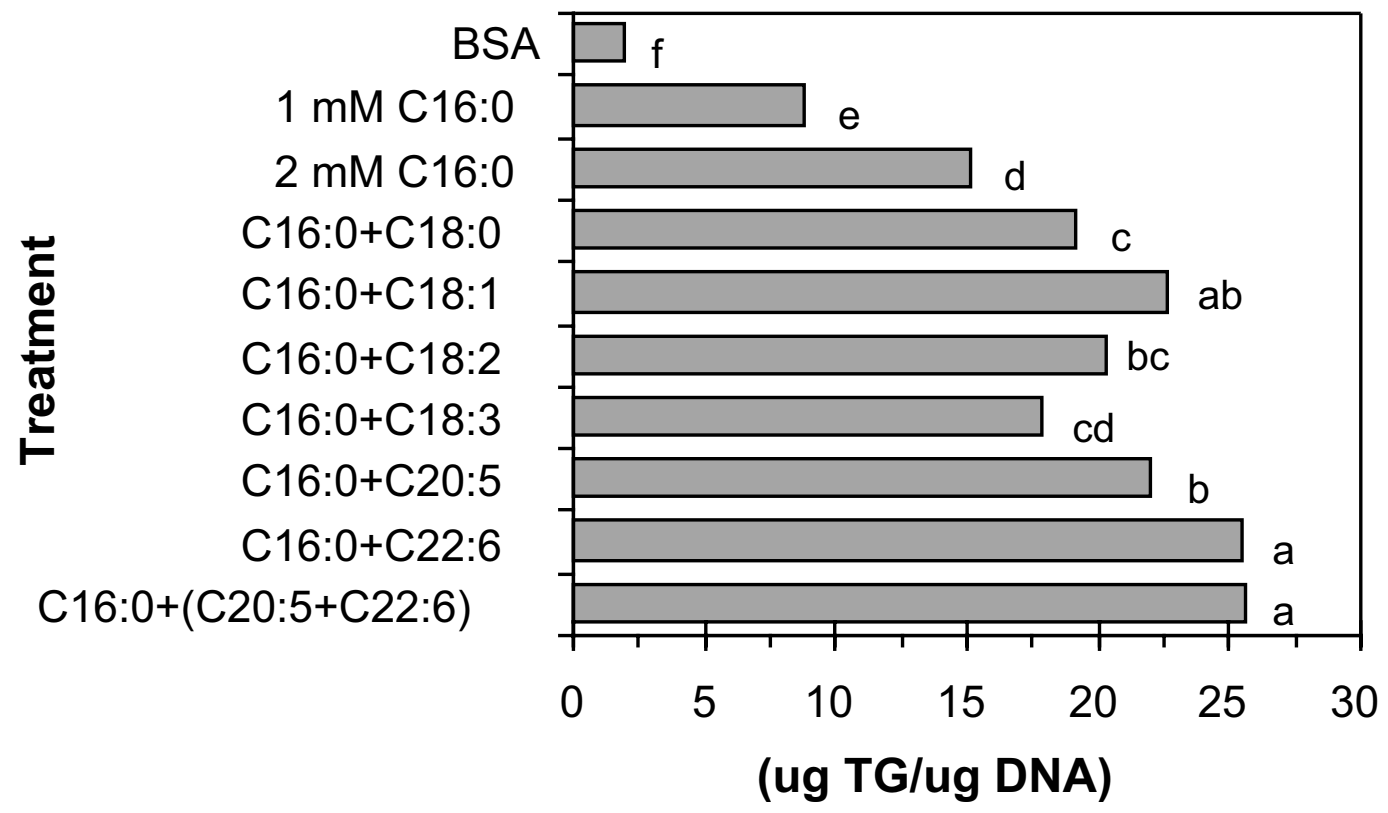

Figure 2. Total cellular triglyceride concentrations. Treatments were bovine serum albumin (BSA) $1 \mathrm{~m} M \mathrm{C} 16: 0,2 \mathrm{~m} M \mathrm{C} 16: 0$, and $1 \mathrm{~m} M$ C16:0 plus $1 \mathrm{~m} M$ of either C18:0, C18:1, C18:2, C18:3, C20:5, C22:6, or 0.5 mM of C20:5 and C22:6. Treatments with unlike letters differ $(P<0.05)$. 
Table 2. Least-squares means for fatty acid composition of cellular triglycerides and phospholipids.

\begin{tabular}{|c|c|c|c|c|c|c|c|c|c|c|}
\hline & $\begin{array}{l}1 \mathrm{mM} \\
\mathrm{C} 16: 0^{1}\end{array}$ & $\begin{array}{l}2 \mathrm{~m} M \\
\mathrm{C} 16: 0\end{array}$ & $\begin{array}{l}\text { C16:0 } \\
\text { C18:0 }\end{array}$ & $\begin{array}{l}\text { C16:0 } \\
\text { C18:1 }\end{array}$ & $\begin{array}{l}\text { C16:0 } \\
\text { C18:2 }\end{array}$ & $\begin{array}{l}\text { C16:0 } \\
\text { C18:3 }\end{array}$ & $\begin{array}{l}\text { C16:0 } \\
\text { C20:5 }\end{array}$ & $\begin{array}{l}\text { C16:0 } \\
\text { C22:6 }\end{array}$ & $\begin{array}{l}\text { C16:0 } \\
\text { C20:5+22:6 }\end{array}$ & SEM \\
\hline & & & & (1 & noles/10 & moles) & & & & \\
\hline \multicolumn{11}{|c|}{ Triglyceride } \\
\hline $16: 0$ & $76.3^{\mathrm{b}}$ & $81.5^{\mathrm{a}}$ & $54.2^{\mathrm{d}}$ & $48.5^{\mathrm{d}}$ & $53.7^{\mathrm{d}}$ & $50.0^{\mathrm{d}}$ & $55.1^{\mathrm{cd}}$ & $51.5^{\mathrm{d}}$ & $59.8^{\mathrm{c}}$ & 2.38 \\
\hline $18: 0$ & $11.5^{\mathrm{b}}$ & $8.5^{\mathrm{c}}$ & $31.9^{\mathrm{a}}$ & $8.2^{\mathrm{c}}$ & $8.8^{\mathrm{bc}}$ & $7.5^{\mathrm{c}}$ & $7.4^{\mathrm{c}}$ & $7.2^{\mathrm{c}}$ & $6.7^{\mathrm{c}}$ & 0.98 \\
\hline $18: 1$ & $7.8^{\mathrm{bcd}}$ & $6.0^{\mathrm{d}}$ & $10.0^{\mathrm{b}}$ & $39.4^{\mathrm{a}}$ & $7.7^{\mathrm{bcd}}$ & $7.6^{\text {bcd }}$ & $8.4^{\mathrm{bc}}$ & $7.8^{\text {bcd }}$ & $7.1^{\mathrm{c}}$ & 1.08 \\
\hline $18: 2$ & $4.3^{\mathrm{c}}$ & $4.3^{\mathrm{c}}$ & $4.3^{\mathrm{c}}$ & $4.2^{\mathrm{c}}$ & $30.4^{\mathrm{a}}$ & $5.8^{\mathrm{bc}}$ & $6.6^{\mathrm{b}}$ & $5.9^{\mathrm{bc}}$ & $5.5^{\mathrm{bc}}$ & 0.65 \\
\hline $18: 3$ & nd & nd & nd & nd & nd & 29.4 & nd & nd & nd & 0.54 \\
\hline $20: 5$ & nd & nd & nd & nd & nd & nd & $20.8^{\mathrm{a}}$ & nd & $7.5^{\mathrm{b}}$ & 1.20 \\
\hline $22: 6$ & nd & nd & nd & nd & nd & nd & nd & $24.3^{\mathrm{a}}$ & $12.9^{\mathrm{b}}$ & 0.82 \\
\hline \multicolumn{11}{|c|}{ Phospholipid } \\
\hline 16:0 & $26.7^{\mathrm{c}}$ & $33.0^{\mathrm{c}}$ & $28.0^{\mathrm{c}}$ & $25.8^{\mathrm{c}}$ & $27.9^{\mathrm{c}}$ & $28.4^{\mathrm{c}}$ & $40.7^{\mathrm{b}}$ & $48.1^{\mathrm{a}}$ & $33.2^{\mathrm{c}}$ & 2.81 \\
\hline $18: 0$ & $52.6^{\mathrm{a}}$ & $47.7^{\mathrm{ab}}$ & $48.4^{\mathrm{ab}}$ & $48.9^{\mathrm{ab}}$ & $42.6^{\mathrm{bc}}$ & $46.8^{\mathrm{ab}}$ & $38.4^{\mathrm{cd}}$ & $23.2^{\mathrm{c}}$ & $34.5^{\mathrm{d}}$ & 3.30 \\
\hline $18: 1$ & $6.8^{\mathrm{b}}$ & $7.6^{\mathrm{b}}$ & $14.5^{\mathrm{a}}$ & $15.3^{\mathrm{a}}$ & $6.8^{\mathrm{b}}$ & $6.9^{\mathrm{b}}$ & $5.0^{\mathrm{b}}$ & $7.4^{\mathrm{b}}$ & $7.5^{\mathrm{b}}$ & 2.22 \\
\hline $18: 2$ & $13.9^{b}$ & $11.8^{\mathrm{bc}}$ & $9.2^{\mathrm{bc}}$ & $9.9^{\mathrm{bc}}$ & $22.6^{\mathrm{a}}$ & $10.8^{\mathrm{bc}}$ & $8.6^{\mathrm{c}}$ & $8.4^{\mathrm{c}}$ & $8.1^{\mathrm{c}}$ & 1.74 \\
\hline $18: 3$ & nd & nd & nd & nd & nd & 9.4 & nd & nd & nd & 1.78 \\
\hline $20: 5$ & nd & nd & nd & nd & nd & nd & $5.1^{\mathrm{a}}$ & $6.1^{\mathrm{a}}$ & $8.3^{\mathrm{a}}$ & 1.79 \\
\hline $22: 6$ & nd & nd & nd & nd & nd & nd & nd & $8.5^{\mathrm{a}}$ & $8.3^{\mathrm{a}}$ & 2.06 \\
\hline
\end{tabular}

${ }^{1}$ Treatments were $1 \mathrm{~m} M \mathrm{C} 16: 0,2 \mathrm{~m} M \mathrm{C} 16: 0$, and $1 \mathrm{~m} M$ C16:0 plus $1 \mathrm{~m} M$ of either C18:0, C18:1, C18:2, C18:3, C20:5, C22:6, or $0.5 \mathrm{mM}$ of C20:5 and C22:6.

${ }^{\mathrm{a}, \mathrm{b}, \mathrm{c}, \mathrm{d}}$ Means within a row with unlike superscripts differ $(P<0.05)$. nd $=$ not detected.

response to supplemental fish or marine oil compared with other fat supplements (Ide et al., 2000; Kim and Choi, 2001; Neschen et al., 2002). Similarly, in vitro studies have found decreased TG synthesis or content when exposing rodent or rabbit hepatocytes to C20:5 or C22:6 (Benner et al., 1990; Madsen et al., 1999). Thus, based upon previous research, treatments containing PUFA would be expected to have lower total cellular TG than the $2 \mathrm{~m} M$ C16:0 treatment rather than higher as in the case of the treatment containing C22:6.

The fatty acid composition of cellular TG is shown in Table 2. The presence of different fatty acids in the medium led to an increase in the percentage of the treatment fatty acid comprising cellular TG, thus indicating direct incorporation of all fatty acids into TG. Following the metabolism of $\left[1-{ }^{14} \mathrm{C}\right]$-labeled fatty acids to TG only accounts for the incorporation of the carboxyl carbon into cellular TG. Therefore, it is plausible that fatty acids could be shortened through oxidative pathways to shorter chain fatty acids, which could be used as substrates for TG synthesis. However, the TG composition data suggests that all fatty acids tested were mostly incorporated directly into cellular TG.

The presence of 0.5 or $1 \mathrm{mM}$ C22:6 in the medium significantly increased $\left[1-{ }^{14} \mathrm{C}\right]$ palmitic acid metabolism to cellular phospholipids compared to all other treatments. Likewise, Baker and Gibbons (2000) showed increased metabolism of $\left[1-{ }^{14} \mathrm{C}\right]$ oleic acid to cellular phospholipids after rats received a fish oil enriched diet compared to a low fat or olive oil enriched diet.

In addition to changes in rates of phospholipid synthesis, treatments also influenced the composition of phospholipids. The percentage of $\mathrm{C} 16: 0$ in cellular phos- pholipids was highest for treatments containing C22:6 and C20:5, which were different from each other and all other treatments. Treatments containing C22:6 followed by C20:5 + C22:6 and C20:5 had the lowest percentage of $\mathrm{C} 18: 0$ contained in their cellular phospholipids. Therefore, treatments containing C20:5 and C22:6 shifted the fatty acid profile of phospholipids by increasing the percentage of $\mathrm{C} 16: 0$ while decreasing that of C18:0. Regardless of treatments, over $70 \%$ of the fatty acids contained in the cellular phospholipid fraction were saturated fatty acids (i.e., C16:0 and C18:0). The changes in phospholipid composition induced by the fatty acids found in fish oils (i.e., C20:5 and C22:6) could have a profound effect on membrane fluidity. Replacing C18:0 with C16:0 and C20:5 or C22:6 in phospholipids would result in more fluid cellular membranes, which can influence a variety of cellular functions (Berdanier, 1988).

Treatments containing C22:6 showed a significant increase in the rate of $\left[1-{ }^{14} \mathrm{C}\right]$ palmitic acid metabolism to cholesterol compared to all other treatments (Table 1). Treatments containing $\mathrm{C} 22: 6$ and $\mathrm{C} 20: 5+\mathrm{C} 22: 6$ increased $\left[1-{ }^{14} \mathrm{C}\right]$ palmitic acid metabolism to cholesterol from 115 to $286 \%$ across all other treatments. These data support previous research that showed C20:5 and C22:6 were poor substrates for metabolism to cholesterol, but both increased palmitic acid metabolism to cholesterol in bovine hepatocytes (Mashek et al., 2002). The increase in palmitic acid metabolism to cholesterol and phospholipids may be explained through changes in the site of oxidation. Fish oil supplementation to rats caused a 3 -fold increase in peroxisomal oxidation of palmitoyl-CoA (Ide et al., 2000). Ad- 
Table 3. Least-squares means for $2.5 \mathrm{mM}\left[2-{ }^{14} \mathrm{C}\right]$ propionic acid metabolism to medium glucose, cellular glycogen and total gluconeogenic products (glucose + glycogen) from 45 to $48 \mathrm{~h}$ after treatments were applied.

\begin{tabular}{|c|c|c|c|c|c|c|c|c|c|c|c|}
\hline & $\mathrm{BSA}^{1}$ & $\begin{array}{l}1 \mathrm{mM} \\
\mathrm{C} 16: 0\end{array}$ & $\begin{array}{l}2 \mathrm{mM} \\
\mathrm{C} 16: 0\end{array}$ & $\begin{array}{l}\text { C16:0 } \\
\text { C18:0 }\end{array}$ & $\begin{array}{l}\text { C16:0 } \\
\text { C18:1 }\end{array}$ & $\begin{array}{l}\text { C16:0 } \\
\text { C18:2 }\end{array}$ & $\begin{array}{l}\text { C16:0 } \\
\text { C18:3 }\end{array}$ & $\begin{array}{l}\text { C16:0 } \\
\text { C20:5 }\end{array}$ & $\begin{array}{l}\text { C16:0 } \\
\text { C22:6 }\end{array}$ & $\begin{array}{l}\text { C16:0 } \\
\text { C20:5+22:6 }\end{array}$ & SEM \\
\hline & \multicolumn{9}{|c|}{$($ nmoles $/ \mu \mathrm{g}$ DNA $\times 3 \mathrm{~h})$} & & \\
\hline Glucose & $2.42^{\mathrm{ab}}$ & $2.19^{\mathrm{ab}}$ & $2.17^{\mathrm{ab}}$ & $2.39^{\mathrm{a}}$ & $2.32^{\mathrm{ab}}$ & $2.27^{\mathrm{ab}}$ & $2.45^{\mathrm{a}}$ & $2.29^{\mathrm{ab}}$ & $1.77^{\mathrm{c}}$ & $2.04^{\mathrm{bc}}$ & 0.19 \\
\hline Glycogen & $1.52^{\mathrm{a}}$ & $1.29^{\mathrm{ab}}$ & $0.96^{\text {cd }}$ & $1.04^{\mathrm{cd}}$ & $1.31^{\mathrm{ab}}$ & $1.19^{\mathrm{bc}}$ & $1.44^{\mathrm{ab}}$ & $1.38^{\mathrm{ab}}$ & $0.95^{\mathrm{cd}}$ & $0.85^{\mathrm{d}}$ & 0.11 \\
\hline Glucose + glycogen & $3.92^{\mathrm{a}}$ & $3.37^{\mathrm{abc}}$ & $3.13^{\text {bcd }}$ & $3.43^{\mathrm{ab}}$ & $3.63^{\mathrm{ab}}$ & $3.46^{\mathrm{ab}}$ & $3.89^{\mathrm{a}}$ & $3.67^{\mathrm{a}}$ & $2.72^{\mathrm{d}}$ & $2.89^{\mathrm{cd}}$ & 0.28 \\
\hline
\end{tabular}

${ }^{1}$ Treatments were BSA, $1 \mathrm{~m} M \mathrm{C} 16: 0,2 \mathrm{~m} M$ C16:0, and $1 \mathrm{~m} M$ C16:0 plus $1 \mathrm{~m} M$ of either C18:0, C18:1, C18:2, C18:3, C20:5, C22:6, or 0.5 $\mathrm{m} M$ of $\mathrm{C} 20: 5$ and $\mathrm{C} 22: 6$.

a,b,c,d Means within a row with unlike superscripts differ $(P<0.05)$.

ditionally, it has been shown that acetyl-CoA generated from peroxisomal oxidation is preferentially incorporated into cholesterol (Hayashi and Miwa, 1989) and phospholipid (Hayashi and Takahata, 1991) synthetic pathways compared to acetyl-CoA generated from mitochondrial oxidation. Therefore, C22:6 may have increased peroxisomal oxidation of $\left[1-{ }^{14} \mathrm{C}\right]$ palmitic acid resulting in increased radiolabel incorporation into cholesterol and phospholipids. There were no significant differences in $\left[1-{ }^{14} \mathrm{C}\right]$ palmitic acid metabolism to cholesterol esters between any treatments. Incorporation of $\left[1-{ }^{14} \mathrm{C}\right]$ palmitic acid to cellular fatty acids was highest for treatments containing $\mathrm{C} 22: 6$ and C18:0, while the lowest rates of incorporation were for the $1 \mathrm{mM}$ C16:0 treatment.

\section{Gluconeogenesis}

Metabolism of $\left[2-{ }^{14} \mathrm{C}\right]$ propionic acid to gluconeogenic products is shown in Table 3. Glucose formation from propionic acid was similar among all treatments with the exception of those containing C22:6. The treatments containing $\mathrm{C} 22: 6$, either at 0.5 or $1 \mathrm{~m} M$, had significantly lower rates of gluconeogenesis to medium glucose. There was no effect of increasing the palmitic acid concentration in the medium from 0 (i.e., BSA) to 1 or $2 \mathrm{~m} M$ on conversion of propionic acid to glucose. Metabolism of $\left[2-{ }^{14} \mathrm{C}\right]$ propionic acid to cellular glycogen decreased for the $2 \mathrm{mM}$ C16:0 treatment compared to the BSA control containing no fatty acids. The lowest rates of $\left[2-{ }^{14} \mathrm{C}\right]$ propionic acid metabolism to cellular glycogen was for treatment C20:5 + C22:6 followed by those containing C22:6, $2 \mathrm{mM}$ C16:0, and C18:0. Similar to glycogen production from propionic acid, total production of gluconeogenic products (glucose + glycogen) decreased when palmitic acid was increased from 0 to 2 $\mathrm{m} M$ in the medium. For the treatments containing a total of $2 \mathrm{~m} M$ fatty acids, the presence of C22:6 in the medium decreased formation of total gluconeogenic products, whereas the numerically highest rates of production were for the treatment containing C18:3.
Previous research has shown that the presence of C18:1 in the medium increased propionic acid metabolism to glucose compared with other long chain fatty acids in $3 \mathrm{~h}$ incubations of bovine hepatocytes (Mashek et al., 2002). The effects of fatty acids and TG accumulation in monolayer hepatocytes are not clear. CadornigaValino et al., (1997) showed decreased propionic acid metabolism to medium glucose in cells infiltrated with TG or exposed to $2 \mathrm{~m} M$ oleic acid. In contrast, Strang et al., (1998) showed that TG infiltration increased propionic acid metabolism to medium glucose and cellular glycogen, but exposure to $1.5 \mathrm{~m} M$ of a physiological mixture of fatty acids had no effect on gluconeogenesis. The authors suggested that the different fatty acids in the medium between the studies might have caused the discrepancies. The results of the current study show a numerical decrease in propionic acid metabolism to medium glucose and a statistically significant decrease in propionic acid metabolism to cellular glycogen and combined gluconeogenic products as palmitic acid is increased from 0 to $2 \mathrm{~m} M$. However, many of the treatments, all of which contained $2 \mathrm{~m} M$ fatty acids, had similar rates of gluconeogenesis compared to the BSA control containing no fatty acids. Therefore, increasing palmitic acid concentration decreased gluconeogenesis, but the decrease may be attenuated depending upon other fatty acids contained in the medium. Additional research is needed to identify the mechanism of how fatty acids regulate gluconeogenesis and to further elucidate the differences between individual fatty acids.

\section{CONCLUSIONS}

The addition of C22:6 to the medium resulted in increased metabolism of palmitic acid to cellular TG, phospholipids, and cholesterol and decreased metabolism of propionic acid to gluconeogenic products. Therefore, C22:6 had the most negative effects on lipid and glucose metabolism in bovine hepatocytes. If the changes observed in vitro apply to in vivo situations, 
then changing the plasma fatty acid profile may have implications for hepatic function and animal health.

Results of the current study are in contrast to the original hypothesis that $\mathrm{n}-3$ fatty acids would increase oxidation of fatty acids and decrease TG content. The saturated fatty acids, C16:0 and C18:0, increased oxidation of fatty acids to ASP. In general, C18:3 elicited the most favorable responses including low cellular TG content and the numerically highest rate of gluconeogenesis. Therefore, fatty acids influenced both lipid and glucose metabolism in monolayer cultures of bovine hepatocytes. However, many of the findings differ from previous short-term $(3 \mathrm{~h})$ incubations. It is possible that the effects of different fatty acids on hepatic function are time-dependent. Perhaps, the beneficial effects of fish oil in short-term cultures are due mostly to their metabolic fate, whereas long-term effects regulate cellular metabolism in a less favorable manner. Future research should test the effects of different fatty acids in vivo and identify the concentrations and time required to achieve the desired effects.

\section{ACKNOWLEDGMENTS}

The authors express their appreciation to Dr. Shawn Donkin for helpful discussion on monolayer cultures and to Sandra Bertics for her technical assistance.

\section{REFERENCES}

Baker, P. W., and G. F. Gibbons. 2000. Effect of dietary fish oil on the sensitivity of hepatic lipid metabolism to regulation by insulin. J. Lipid Res. 41:719-726.

Benner, K. G., S. Sasaki, D. R. Gowen, A. Weaver, and W. E. Connor. 1990. The differential effect of eicosapentaenoic acid and oleic acid on lipid synthesis and VLDL secretion in rabbit hepatocytes. Lipids 25(9):534-540.

Berdanier, C. D. 1988. Role of membrane lipids in metabolic regulation. Nutr. Rev. 46(4):145-149.

Bruss, M. L. 1993. Metabolic fatty liver of ruminants. Adv. Vet. Sci. Comp. Med. 37:417-449.

Cadorniga-Valino, C., R. R. Grummer, L. E. Armentano, S. S. Donkin, and S. J. Bertics. 1997. Effects of fatty acids and hormones on fatty acid metabolism and gluconeogenesis in bovine hepatocytes. J. Dairy Sci. 80:646-656.

Clarke, S. D. 2000. Polyunsaturated fatty acid regulation of gene transcription: A mechanism to improve energy balance and insulin resistance. Brit. J. Nutr. 83(1):S59-66.

Donkin, S. S., and L. E. Armentano. 1993. Preparation of extended in vitro cultures of bovine hepatocytes that are hormonally responsive. J. Dairy Sci. 71:2218-2227.
Folch, J., M. Lees, and G. H. Sloane Stanley. 1957. A simple method for the isolation and purification of total lipids from animal tissues. J. Biol. Chem. 226:497-509.

Hayashi, H., and A. Miwa. 1989. The role of peroxisomal fatty acyl$\operatorname{CoA} \beta$-oxidation in bile acid biosynthesis. Arch. Biochem. Biophys. 274(2):582-589.

Hayashi, H., and S. Takahata. 1991. Role of peroxisomal fatty acylCoA $\beta$-oxidation in phospholipid biosynthesis. Arch. Biochem. Biophys. 284(2):326-331.

Herdt, T. H. 1988. Fatty liver in dairy cows. Vet. Clin. North Am. Food Anim. Pract. 4:269-287.

Hue, L., F. Bontemps, and H. G. Hers. 1975. The effect of glucose and of potassium ions on the interconversion of the two forms of glycogen phsophorylase and glycogen synthetase in isolated rat liver preparations. Biochem. J. 152:105-114.

Ide, T, H. Kobayashi, L. Ashakumary, I. A. Rouyer, Y. Takahashi, T. Aoyama, T. Hashimoto, and M. Mizugaki. 2000. Comparative effects of perilla and fish oils on the activity and gene expression of fatty acid oxidation of enzymes in rat liver. Biochim. Biophys. Acta. 1485:23-35.

Ikeda, I., J. Y. Cha, T. Yanagita, N. Nakatani, K. Oogami, K. Imaizumi, and K. Yazawa. 1998. Effects of dietary $\alpha$-linolenic, eicosapentaenoic, and docosahexaenoic acids on hepatic lipogenesis and $\beta$-oxidation in rats. Biosci. Biotechnol. Biochem. 62(4):675-680.

Kim, H., and H. Choi. 2001. Dietary $\alpha$-linolenic acid lowers postprandial lipid levels with increase of eicosapentaenoic and docosahexaenoic acid contents in rat hepatic membrane. Lipids. 36(12):1331-1336

LaBarca, C., and K. Paigen. 1980. A simple, rapid, and sensitive DNA assay procedure. Anal. Biochem. 102:344-352.

Madsen, L., A. C. Rustan, H. Vaagenes, K. Berge, E. Dyroy, and R. K. Berge. 1999. Eicosapentaenoic and docosahexaenoic acid affect mitochondrial and peroxisomal fatty acid oxidation in relation to substrate preference. Lipids 34:951-963.

Mashek, D. G., and D. K. Beede. 2001. Peripartum responses of dairy cows fed energy-dense diets for 3 or 6 weeks prepartum. J. Dairy Sci. 84:115-125.

Mashek, D. G., S. J. Bertics, and R. R. Grummer. 2002. Metabolic fate of long chain unsaturated fatty acids and their effects on palmitic acid metabolism and gluconeogenesis in bovine hepatocytes. J. Dairy Sci. 85:2283-2289.

Mills, S. E., L. E. Armentano, R. W. Russel, and J. W. Young. 1981. Rapid and specific isolation of radioactive glucose form biological samples. J. Dairy Sci. 64:1719-1723.

Neschen, S., I. Moore, W. Regittnig, C. L. Yu, Y. Wang, M. Pypaert, K. F. Petesen, and G. I. Shulman. 2002. Contrasting effects of fish oil and safflower oil on hepatic peroxisomal and tissue lipid content. Am. J. Physiol. Endocrinol. Metab. 282:E395-401.

SAS User's Guide: Statistics. Version 7.1 Edition. 1999. SAS Inst., Inc., Cary, NC.

Sessler, A. M., and J. M. Ntambi. 1998. Polyunsaturated fatty acid regulation of gene expression. J. Nutr. 128:923-926.

Strang, B. D., S. J. Bertics, R. R. Grummer, and L. E. Armentano. 1998. Effect of long-chain fatty acids on triglyceride accumulation, gluconeogenesis, and ureagenesis in bovine hepatocytes. J. Dairy Sci. 81:728-739.

Sukhija, P. S., and D. L. Palmquist. 1988. Rapid method for determination of total fatty acid content and composition of feedstuffs and feces. J. Agric. Food Chem. 36:1202-1206.

Veenhuizen, J. J., J. K. Drackley, M. J. Richard, T. P. Sanderson, L. D. Miller, and J. W. Young. 1991. Metabolic changes in blood and liver during development and early treatment of experimental fatty liver and ketosis in cows. J. Dairy Sci. 74:4238-4253. 